\title{
Living Labs, vacancy, and gentrification
}

Paolo Cardullo and Rob Kitchin,

NIRSA, National University of Ireland Maynooth, County Kildare, Ireland.

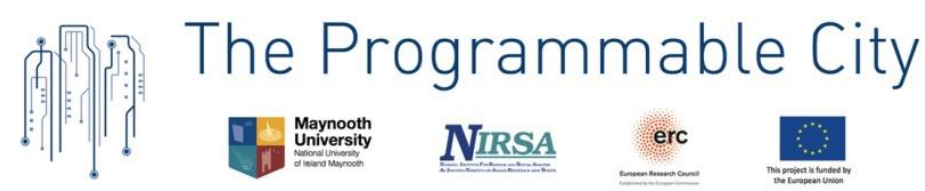

The Programmable City Working Paper 28

http://progcity.maynoothuniversity.ie/

16 March 2017

Prepared for 'The New Urban Ruins: Vacancy and the Post-Crisis City' workshop, 1-3 March 2017, Trinity College Dublin.

Published as an open access pre-print on SocArXiv: https://osf.io/preprints/socarxiv/waq2e

\begin{abstract}
This paper evaluates smart city (SC) initiatives in the context of re-using vacant property. More specifically, we focus on living labs (LL) and vacancy in general, as well as on their potential role in fostering creative economy-fuelled gentrification. LL utilise Lo-Fi technologies to foster local digital innovation and support community-focused civic hacking, running various kinds of workshops and engaging with local citizens to co-create digital interventions and apps aimed at 'solving' local issues. Five approaches to LL are outlined and discussed in relation to vacancy and gentrification: pop-up initiatives, university-led activities, community organised venues/activities, citizen sensing and crowdsourcing, and tech-led regeneration initiatives. Notwithstanding the potential for generating temporary and independent spaces for transferring and fostering digital competences and increasing citizens' participation in the SC, we argue that LL largely foster a form of participation framed within a model of civic stewardship for 'smart citizens'. While presented as horizontal, open, and participative, LL and civic hacking are often rooted in pragmatic and paternalistic discourses and practices related to the production of a creative economy and a specific version of SC. As such, by encouraging a particular kind of re-use of vacant space, LL potentially contributes to gentrification pressures within locales by attracting the creative classes and new investment. We discuss these approaches and issues generally and with respect to examples in Dublin, Ireland.
\end{abstract}

Key words: vacancy, property, gentrification, living labs, civic hacking, creative class, regeneration 


\section{Introduction}

"Living Labs are defined as user-centred, open innovation ecosystems based on a systematic user co-creation approach integrating research and innovation processes in real life communities and settings. In practice, Living Labs place the citizen at the centre of innovation, and have thus shown the ability to better mould the opportunities offered by new ICT concepts and solutions to the specific needs and aspirations of local contexts, cultures, and creativity potentials." (European Network of Living Labs, ENOLL, our emphasis) ${ }^{1}$

The Living Labs (LL) concept is generally intended as a bottom-up approach to the smart city (SC), designed to increase citizens' participation and involvement in 'solving' local issues. LL utilise Lo-Fi technologies to foster local digital innovation and support community-focused civic hacking, running various kinds of workshops and engaging with local citizens to cocreate digital interventions and apps. LL were born in the open design tradition of MIT's experimentation with space-aware technologies: fostered by the idea that digital technologies should first be tested by their users 'in-vivo settings' (Dutilleul et al. 2010). LL were given a primary role in the development of SC in 2006 when the European Commission decided to 'put the user in the driver's seat' of the innovation process (EC 2009, cited in Dutilleul et al. 2010). In contrast to the American tradition of 'design for' users, LL were intended as a participatory experiment of 'design with' and 'design by' users (Schuurman et al. 2016). In other words, there was a notable shift from passive user feedback to a more active approach based on users' involvement (co-creation or participatory design). LL approach therefore situates the SC as a testbed for experimenting with the design and use of digital technologies in situ. Here, the SC is recast in two ways. First, as being in fieri, a beta version in need of testing through trialling, where smart infrastructures are 'white-boxed', layer by layer (Corsin Jimenez 2014). Second, as being citizen-centric, a more open, affordable, and democratic endeavour, developed from the bottom-up around the needs and desires of local residents, with LL supplying the necessary skills and competences to citizens (Sartori 2015).

The promoters of LL highlight three important characteristics that enable such a vision of SC. Firstly, LL are a context-based experience, which is difficult to replicate in the same way elsewhere: the approach focuses on a localized environment and specific technologies (Clark and Shelton 2016). Secondly, LL are temporality contingent, framed with respect to the temporal cycles of projects, technologies and funding, and often run the risk of shifting a focus away 'from place-making to creating temporary events' (Lange and de Waal 2013). Thirdly, LL are intended to operate as multi-stakeholder endeavours that include local

1 http://www.openlivinglabs.eu/aboutus 
residents, acting as a counter-weight to the techno-centric, top-down approach to SC initially forwarded by big business by promoting a more holistic approach that places citizens at its centre. Ultimately, the ambition for some is that the SC will eventually boast a model of governance in which 'a community assumes political and expert management over its infrastructures' (Corsin Jimenez 2014).

We present five examples of LL - pop-up events, university-led activities, community organised venues/activities, citizen sensing and crowdsourcing, and, tech-led regeneration initiatives - discussing each in the context of addressing issues of urban vacancy; that is, reusing empty public and private buildings that are awaiting re-allocation following abandonment in the boom/bust cycles of urban development (Kitchin et al. 2015; O'Callaghan and Lawton 2016). For each, we briefly discuss their potentials for the creation of temporary and independent spaces, the generation of digital competences, and fostering citizens' participation in 'solving' local issues; we additionally foreground the risk of gentrification they carry. Notwithstanding the potential of LL to foster locally-focused and user-centric smart cities, in the conclusion we consider how best to frame the participation and governance of living labs that minimizes gentrification effects, and raise a series of questions for further research.

In the definition of LL quoted at the start of the paper, there is an evident slippage between the 'user-centric' model of LL and its assumed 'citizen-centric' nature. We therefore begin to ask, what model of governance is operating in different forms of LL? Are LL really promoting horizontal, open, and participatory SC or, rather, is their ethos rooted in pragmatic and paternalistic discourses that enact a form of civic stewardship for 'smart citizens'? We thus ask whether LL really realise the bottom-up ethos of SC they promise, as 'co-creation and appropriation of innovations by users' (Ballon et al. 2015), or rather they foreground an urban environment, and specifically 'urban development districts'(PCAST 2016), primed for the 'creative class' (see Castelnovo et al. 2015; Clark and Shelton 2016; Florida 2007)? What kind of citizens do LL attract?

\section{The pop-up city}

The notion of 'pop-up urbanism' has a relatively short history, linked to the recent disastrous earthquakes in Christchurch, New Zealand (2010-11). Here, a group of non-for-profit organisations started re-building parts of the destroyed city using low-cost, gerry-rigged solutions to create new spaces or reclaim damaged ones, usually for leisure and entertainment 
purposes but also for work. ${ }^{2}$ This approach to temporary space-making has, however, a longer tradition in: tactical urbanism for play-and-disruption - from the Situationist International since the 1950s (Bonnett 2006) to more contemporary search for serendipity and discovery (Foth 2016; Zuckerman 2016); DIY urbanism, where participants directly intervene in projects (see Till and McArdle 2016); and hackable urbanism, in which urban space is not seen as given, but as moving elements that can be repurposed (see Cardullo 2014; Corsin Jimenez 2014; Lange and de Waal 2016; Garrett 2013; Schmidt 2011). These temporary interventions in city space draw on multiple motivations, including community building, civic participation, artistic intervention, alternative media practices, and guerrilla urbanism. They work well with the spatio-temporal dimension of digital interactions, which involves fast, transitory, and sometimes ephemeral connections (Lange and de Waal 2013). This spatiotemporal dimension is often deemed as 'hybrid', in-between 'real' and virtual spaces of the everyday (Antoniadis and Apostol 2014; Lange and de Waal 2013).

Most pop-up projects involve social media platforms as an interface between participant stakeholders, technology, and places. They typically work around specific and contingent problems, such as a particular plot for development, an artistic event, or a hackathon. They are sometimes dependent on proximity - for example, in the case of Wi-Fi connectivity (see Cardullo 2017). An example of pop-up LL is the Fostering Digital Participation Project, which in 2015 set up mobile containers units that travelled across Australia. ${ }^{3}$ A Dublin City Council initiative, Dublin Beta has run a number of street-based pop-up initiatives working with citizens, though most are low- or no-digital tech in nature (such as pop-up parks and secure bike sheds in parking bays, new gutter run-off systems, painting street infrastructure to discourage vandalism) (Perng 2016). Also in the city, a diverse range of pop-ups are being facilitated through a web platform, 'fillit', that aims to match vacancies and pop-up events: 'for people looking for the perfect temporary venue for events, pop-ups, retail, promotions and everything in-between'. ${ }^{4}$ 'fillit' displays a business model similar to AirBnB, but with a twist: if the vacancy is listed for free, 'fillit' does not charge a fee either, because it also aims at 'inspiring theatre groups, youth centres, the arts or startups'.

The benefits of flexible and affordable pop-up initiatives, techno-sheds similar to mobile cycle surgeries, or beta projects, are however to be set against the local context, their temporality, and the risk of further boosting the displacing effects of creative economy. In

2 See http://sustainablecities.org.nz/2014/02/stories-of-urban-recovery-from-christchurch/

3 http://digitalparticipation.net.au/methodology/

4 https://www.fillit.ie/ 
fact, as de Lange and de Waal suggest, pop-up LL projects embody a 'shift from manipulating space to manipulating space in time' (2013). A key problem with the transitory character of a pop-up is thus its ontological nature: the vast majority of urban dwellers probably do not live, or want to live, in pop-up cities; neither might they want to dwell in temporary 'hybrid' locations, but in actually-serviced cities. In order to participate to pop-up LL, citizens are in fact required to be pro-active, engaged, and ready to play in any up-and-coming event. Moreover, participant citizens are assumed to be already in possession of, or are willing to receive, the cultural capital necessary to enable them to participate. This opens up a new problem, more relevant to the theme of urban vacancy and gentrification.

Pop-up LL are usually directed toward a specific audience, rich in cultural and social capitals as well as in time. These are scarce currencies in modern urban living, more available to some people than others. This paradox of digital inclusion and digital divide is sometimes made explicit in the SC literature. For instance, according to Castelnovo et al. (2015), smart cities offer a unique possibility of becoming 'organic ecosystems in which end-users and other relevant urban stakeholders are collaboratively involved in co-design, co-decision, coproduction and co-evaluation'. They further suggest that making cities smart is necessary in order to create 'a climate suitable for an emerging creative class'. Their 'holistic' view on smart cities is here translated into a platform for the digitally-literate middle-class of urban creatives, social innovators and professionals. This view re-proposes Florida's assumption that cities need to change towards a flexible and 'urban cool' business model in order to attract the creative class (Florida 2007; see Lawton et al. 2014). Understanding the forms and distribution of digital labour and the extent to which they contribute to smart cities is therefore crucial.

Pop-ups can help initiate change in the property and economic landscape and feel of an urban area, but can also determine cultural and exclusionary displacement effects on disadvantaged classes (see Marcuse 1985; Slater 2006). Here, pop-ups can operate as a double-edged sword. On the one hand, they can transform place to appeal to the generation of hipster millenials, with the almost inevitable gentrifying consequences. On the other hand, they can aid local artists, civic hackers and socially creative people who become stuck in the paradox of urban regeneration. Slater and Iles (2009) capture this paradox: 'Neither able to successfully collude due to art's lingering requirement for autonomy, nor to effectively opt out (street art becomes gallery art becomes street art, etc.), the artist working in the maelstrom of regeneration registers, either critically or not, the social war it entails'. In this context, it is relevant to mention that Dublin independent pop-up spaces - carved in the niches of the city 
rapid boom-and-bust housing policy of early 2000s (Kitchin et al., 2015) -are a recent tradition of eclectic and lively, but politically non-radical spaces (Bresnihan and Byrne 2015).

\section{The digitally literate city}

The second kind of LL that can occupy vacant property is a university-led Lab. This typically involves long-term educational activity with targeted groups, such as young students. In the case of Dublin, Dublin City University has run coderdojo sessions since 2012, including coding, making, games development, and also runs specific sessions for girls. ${ }^{5}$ On its innovation campus, DCU has also partnered with TechShop, a 'membership-based workshop and fabrication studio that provides access to machines, tools, software', and a 'community of creative people, classes, workshops, instruction and meet-ups' for 'digital and hardware innovators and entrepreneurs in Dublin'. The innovation campus is a refurbished former vacant space that used to occupied by a state agency, but is now university property.

Another example of university-led Lab was Officina Emilia (OE, Modena 2000-15), an action-research and museum-lab for the regeneration of competencies in mechanical industries. ${ }^{6}$ Its objective can be summarised as 'linking science, technology, engineering, mathematics and social sciences in a more effective way through the design of relationships, tools, and innovative pilot actions' (Mengoli and Russo 2017). The Officina - which in the Italian Operaist tradition means 'sweatshop' - was connected with schools, teachers, and the SME sector, and its activity sometimes became part of local schools' curriculum. More importantly for the theme of this paper, OE was located in a vacant industrial warehouse in the middle of Modena's Artisan Village, a place and a city with a long tradition of workingclass and co-operative presence. After 15 years of intense activity, OE and its Museum-Lab had to close due to a change in policy of its principal funding bodies, the Emilia-Romagna Region and the University of Modena and Reggio Emilia.

The timeline on which the OE cycle is set offers some space for analysis. During the last few years, in fact, Italy has been at the forefront of the SC discourse (Vanolo 2014): in particular, the City and University of Bologna, capital of Emilia-Romagna, have devolved significant funding to SC initiatives that include 'the citizen'. In 2012-14, parallel to a large marketing campaign, the city re-launched the civic network Iperbole 2020, focused on 'community needs'. ${ }^{7}$ It is bewildering that, in a climate in which City and University struggle to start-up smart inclusive projects, a well-established Lab for the regeneration of (digital)

5 http://coderdojodcu.com/

6 http://www.officinaemilia.unimore.it/site/home/in-english.html

7 http://iperbole2020.comune.bologna.it/smartcity/ 
competences is closed. This paradox brings us to the crucial role of governance at the heart of the SC. In increasingly competitive cities the provision of free or affordable vacant premises can be crucial to the sustainability of inclusive LL projects.

City vacancies can be a host of all sorts of interesting projects that boast community engagement and citizens' participation. However, they depend upon political will and the creation of flexible institutional tools - for instance, wireless networks without login details (see Agyeman and McLaran 2013). An example is offered by the City of Seoul, which gives some of its properties for community events, during weekends or for a determinate period, as well as offering an institutional climate favourable to sharing common resources and skills. ${ }^{8}$ In other words, we would agree cities can be shared better by enabling 'good governance and collective city structures', as an interface between different interests and diverse publics (McLaren and Agyeman 2015). This interface cannot be exclusively centred on digital technologies, social media, and complex datasets. These instruments greatly help communication, as well as influence place-making and the organisation of 'the city as a society' (de Waal 2014). However, LL also requires an old-fashioned but crucial element: a place made of brick and mortar, with affordable services and utility bills. Needless to say, the pool of vacancies currently experienced by the City of Dublin can be a facilitator in this sense.

\section{The communal city}

LL initiatives are medium-term interventions in local neighbourhoods that echo the traditional ethos and organization of community/social centres. This kind of LL usually rotate around well-known members in a community of interest, who often act as 'benevolent dictators' in the various projects. These are civic hackers or community advocates who provide the stewardship necessary to connect people and possess strong technical skills with respect to building and maintaining networked hardware and software applications. These sort of LL, sometimes a hacker-space or art-space, are hosted in either vacant public or private space, but often seek to maintain the characteristics of an 'independent space'. In both cases, rent can be a crucial factor for the sustainability of the project (Bresnihan and Byrne 2015). ${ }^{9}$ These LL typically undertake a rolling set of projects that seek to address specific problems, such as WiFi connectivity (Cardullo, 2017), civic apps (Perng and Kitchin 2016), or planning applications (Lange and de Waal 2016). Examples of such initiatives in Dublin are Tog, a maker-space that includes digital projects, and Code for Ireland that meets monthly to develop

8 http://english.seoul.go.kr/policy-information/key-policies/city-initiatives/1-sharing-city/

9 The Dublin-based maker space TOG, for instance, charges a 45 Euro monthly membership fee, mostly to cover rent and utility bills: https://www.tog.ie/membership 
civic apps, though it has no permanent space, its meet-ups migrating between the corporate offices of Google, Facebook and LinkedIn (see Perng and Kitchin 2016).

It is reasonable to suggest that such forms of civic hacking, with medium-term investment in a specific community of interest, might have a limited or even negative effect towards gentrification and cultural displacement. In his ethnographic account of the Open Wireless Network (OWN) in inner-city London, Cardullo (2017) shows how wireless communication was of secondary importance to the locals who joined the network. More importantly, for years OWN contributed to community-building and other forms of face-toface interventions, to local knowledge exchange and transfer of competences, as well as to some instances of anti-gentrification activism. What the ethnography of OWN also suggests is that making 'community' operative, especially around digital technologies, requires a great deal of stewardship: time and funding for maintenance, management, and investment in cultural and social capitals.

The experience of OWN contradicts the notion that technology should be the automatic interface for bottom-up SC projects by increasing civic participation and access to city governance, an idea that often surfaces in the SC debate. Civic hackers and enlightened professionals rather provide the 'magic' of community relations, heavily influencing projects working and outcomes. This type of LL are in fact based on trust and social interfacing that is accrued over time. However, time seems to be structurally lacking in projects that rely on new media to tackle local issues (see Lange and de Waal 2013). In other words, the transitory character of the 'event' around which community-based activities are mobilised (planning applications, civic hacking, or artistic projects) raises questions in terms of the long-term sustainability of community relations activated through LL strategy.

\section{The crowdsourced city}

A fourth type of LL concerns the gathering of meaningful data via smart sensors or via citizens' reporting. The urban landscape becomes the living laboratory, with participants practising citizen science initiatives aimed at better understanding local conditions, or being enrolled as citizen sensors. Examples of such endeavours include Sensornet, ${ }^{10}$ which pooled together sensor data of air traffic noise in Amsterdam, and the TrackTrash project by MIT, ${ }^{11}$ that tracked the paths of trash deposed in New York. In these cases, citizens' participation is demanded for the installation of monitoring sensors, but the experiments do not require continuous active engagement: once installed the sensor generates data regardless, though

10 http://www.sensornet.nl/english/

11 http://senseable.mit.edu/trashtrack 
citizens may be involved in data analysis and acting upon the data. Alternatively, citizens may be enrolled as passive citizen sensors, for example, their smartphones being tracked across a city by a sensor network to better understand footfall and movement patterns. Here, the citizen is a data-point: governance is not so much around a territory, but 'through enabling the connections and processes of everyday urban inhabitations within computational modalities' (Gabrys 2014). In general, such data has little to do with vacancy, other than providing data on certain conditions within which vacant property resides.

In contrast, crowdsourcing projects are being used to identify vacant property, relying on users' inputs to generate pertinent data. Such forms of crowdsourcing usually work by piping data from Google Map or Open Street Map into a mobile app, with vacant units and associated details and photos being located on the map. A couple of different crowdsourced initiatives relating to vacancy have been undertaken in Dublin. The first was initiated by a small group who walked around the city, noted vacant units and uploaded them to a dedicated Google Maps page. ${ }^{12}$ This was then followed by Re-Using Dublin, ${ }^{13}$ in which users can explore vacant sites or add any they have discovered. Other related sites include Inside Airbnb $^{14}$ that details the properties that are not in permanent use but are let through Airbnb lettings, the AIRO mapping module ${ }^{15}$ on vacant housing identified in Census 2011, and Dublin City Council Derelict Sites register ${ }^{16}$ - though these last examples are fixed and static sites, accessible to citizens, but not updatable by them.

The problem of crowdsourcing projects is maintaining contributors' motivation and enthusiasm, with the site often lapsing into a static and out-of-date service (Dodge and Kitchin 2013). Indeed, other cities have not managed to maintain the momentum of citizens' participation, with our searches for similar projects often leading to a '404 error' (page not found), or to 'dataset not available' notices. ${ }^{17}$ In other cases - such as ZO!City platform in Amsterdam, ${ }^{18}$ which matches start-up regeneration initiatives and vacancies in the ethnic diverse and relatively poor district of Bijlmere (see Aalbers 2011) - public entries and participation are limited (one or two 'likes', comments or shares) while the effects of the initiatives seem to be having a larger and long-lasting impact on the area. ${ }^{19}$ Somewhat

12 For an account see https://www.thejournal.ie/derelict-sites-in-dublin-get-mapped-969180-Jun2013/

13 http://www.reusingdublin.ie

14 http://bit.ly/2lHzKNJ

15 http://airo.maynoothuniversity.ie/mapping-resources/overview

16 https://data.gov.ie/dataset/derelict-site-register

17 For example, this seems to be the case for the city of Bologna: http://dati.comune.bologna.it/immobiliinutilizzati

18 http://www.zocity.nl/

19 The project is part of the EU-Smarcities flagship project TransformCity and aims to convert the current $30 \%$ vacancy rate of Amstel3 into a 'lively mixed-use urban neighbourhood', a '24/7 lively city quarter where 
ironically, one effect of crowdsourcing vacancy is to identify investment opportunities for gentrification.

We would argue many of these 'citizen-centric' initiatives seem to act like a smokescreen around the SC: they are hyper-visible, compared to their actual impact and effective participation, and this can be attributed to the large social media presence these initiatives have. The reliance on citizens, the unsustainability of crowdsourcing initiatives and the failure of the city to display their own vacant properties bring us once more to the issue of governance. Who is responsible for urban vacancy? Who is controlling the SC? To what extent can citizens impact on how space is calculated and used? And once data are collected and analysed, who has the political capital to meaningfully act upon the data? (see Gabrys, 2014).

\section{The regenerated city}

For advocates of SC, one of the key reasons for developing and implementing SC initiatives is to help grow and sustain local economies through attracting foreign-direct investment and fostering start-ups and indigenous SMEs. The digital economy is seen as a key sector for generating new employment and SC initiatives a means to attract talented workers and facilitate economic activity, as well as being a new market opportunity. Digital businesses need to locate in an ecosystem of suitable office buildings with high quality technical systems, a strong concentration of business and support services, and a pool of suitable labour. One way to create these conditions is to regenerate an existing city area, one that occupies a central site near to key transport links and other business services, repurposing or replacing existing buildings. In the case of Dublin, there are a number of localised agglomerations of digital companies. Some of these have been built on greenfield sites on the edge of the city, such as Sandyford, Citywest, and Blanchardstown. In the city centre there are two key sites of agglomeration, both of which are regeneration initiatives, redeveloping old, largely vacant or former industrial sites: The Digital Hub and Silicon Docks.

The Digital Hub ${ }^{20}$ was established in 2003 and is managed by the Digital Hub Development Agency. It is located to the west of the city centre in the Liberties, an area of long-standing social deprivation. The Digital Hub itself is housed in eight former buildings of the Guinness factory site and supports circa 90 companies employing between them 800 to 1000 employees, as well as the NDRC, a state-backed early stage investor and accelerator for

you can work, live, learn and play'. One of the few completed projects to date is this pop-up brewery:

http://brouwerijkleiburg.nl/

20 https://www.thedigitalhub.com/ 
tech start-up companies. As companies grow, they leave to find their own premises to be replaced with new start-ups or SMEs (nearly 200 companies have been supported to date). The Digital Hub is also a key agent in local regeneration, using a public-private partnership model to redevelop and invest in local property stock, including student accommodation, restoring Georgian buildings and other industrial and brownfield sites for office space. Its ambition is to develop a vibrant digitally-driven economy in the area, but part of its remit is also support the local community. To this end it has participated in what might be considered LL initiatives including a joint programme with the National College of Art and Design, located nearby, to teach local kids to be 'future creators', working with local schools on the 'connected classroom', and supporting community initiatives such as LAMP (Local Asset Mapping Project) concerning older people's health.

Silicon Docks is located to the east of the city centre around Grand Canal basin and the old Dublin docks on the northern and southern side of the River Liffey. The area was initially part of the strategic development zone overseen by Dublin Docklands Development Agency (DDDA), which operated from 1997 to May 2012. In late 2012 a smaller, revised Docklands SDZ (Strategic Development Zone) was created. While the original area included older, residential communities, the new Docklands SDZ's boundaries have been drawn to exclude such communities and, when completed, it is anticipated that it will include only 2300 residential units, most of them newly build, high-end apartments (O'Hara 2015). The Docklands SDZ is already home to the European headquarters of many global IT companies including Google, Facebook and LinkedIn. It has also been recently designated a 'smart district', an area-based LL for trialling new SC technologies such as sensor networks, smart lighting, smart grids, etc. (Heaphy and Pétercsák 2016). Although dominated by large multinationals, the area is also home to numerous tech start-ups and incubator space such as Dogpatch Labs. Community-focused initiatives include Code for Ireland, though many of the participants are workers employed by companies in the area, rather than residents traditionally located nearby (that is, the participants are largely part of the gentrifying class).

In both cases, the primary focus is on growing the digital economy and regenerating the area into a vibrant economic zone. While there are some attempts to engage with local communities through LL initiatives, they are largely tokenistic attempts to play out good corporate social responsibility, as opposed to creating a SC from the bottom-up. This seems to be a feature of other urban development districts too, such as the redeveloped Navy Yards in Philadelphia (Shelton et al. 2015), the Innovation District in Boston, and the 'cultural quarter' of Shoreditch in London. Here, rather than local communities fully benefiting from economic revitalisation, the creative class are being drawn into these new digital hubs displacing 
existing residents through soaring rental and property prices. The well-researched dynamics of cultural and exclusionary displacement seem to operate here too (Marcuse 1985; Slater 2006). As such, these areas are key active sites of gentrification where local authorities purposively seek gentrification as an ideal policy solution for urban change (Lawton and Punch 2014).

\section{Concluding remarks}

All of the LL interventions highlighted in this paper supposedly seek to address the pressing issue of citizens' engagement, participation, and control in the SC. Lange and de Waal (2013) go further, suggesting the LL approach can foster city 'ownership', that is, in their own words, 'an inclusive form of engagement, responsibility and stewardship' of 'what belongs to us all'. Stewardship can be seen as an ethics that implies planning and managing resources on behalf of all citizens. It can be enacted by a body on behalf of people - such as a city council, a LL, or a development agency - or be enacted collectively by those people themselves. Either form of proactive caring for the urban commons might well be seen as a desirable feature of urban citizenship, the res publica ethos.

However, such responsibility might not be welcome by all, and neither is it always as inclusive as it might at first seem. This is because stewardship and participation require the investment of time, labour, and availability: these are scarce forms of currency in most urban dwellers' lives. Moreover, what is seen as a desirable outcome is contested across groups. Stewardship enacted on behalf of others can easily slip into civic paternalism; that is, elites deciding what is best for citizens. Inevitably, any initiative undertaken works to serve the interests of some groups vis-à-vis others. The question with respect to LL is whether the different forms outlined above work to create a bottom-up, citizen-led, participatory and inclusive smart city - repurposing vacant property and digital technologies to the benefit of local communities - or ultimately work to serve the interests of capital and foster the processes of gentrification by attracting middle-class creative and mobile workers while displacing local residents?

SC supporters put a lot of emphasis on the city as a testbed for smart projects. The Obama Administration's report on SC, for instance, recently suggested that 'Urban Development Districts are Living Laboratories from which fundamental knowledge about urban processes and practical implementation practices can be learned, adapted, and generalized to other districts' (PCAST, 2016: 16). For Clark and Sheldon (2016), UDDs rather promote 'smart enclaves' for exceptional citizens, which are thought to eventually trickle- 
down to the rest of the city. ${ }^{21}$ An example of this vision can be already seen in NYC Hudson Yards (Mattern 2016) or Seoul Songdo (Kitchin 2016). ${ }^{22}$ It is somehow revealing that the aforementioned report (PCAST 2016, 23) initiates the history of 'urban science' with Ebenezer Howard's 1898 'Garden City', a pioneering work in urban utopianism and New Urbanism movement. A dominant version of the SC thus seems to understand LL as central to an ongoing process of 'modernisation': this shift is achieved by extending pioneering smallscale projects, design-focused LL, and an entrepreneurial culture of open innovation, to the overall organisation of urban space and living.

In this paper we have examined some LL initiatives which are much smaller in scale and scope, transitory in time, and generally more suitable for the creation of alternative spaces in which citizens digital rights are fostered and enhanced. As grassroot experimentation with digital technologies, DIY urbanism, and participatory planning, some LL initiatives seem to meet urban vacancies both in space and time, creating a patchwork of interventions in complex ecologies of city change. In this context, some LL projects probably have a minimal impact on the gentrification of cities, increasing social and cultural capital of participants and, therefore, limiting gentrification displacement effects. The case study of the 'communal city' offered some glimpses of good practice around the development of medium-term forms of engagement around a community of interest. This type of initiative are sometimes able to build trust in participants and, due to their long-standing investment, also transfer forms of capital necessary to enable participation from a variety of local people. These projects usually hinge around well-known community advocates or civic hackers; around a place easy to identify within a neighbourhood, such as a social/cultural centre; and around activities that enhance the use-value of a resource or an infrastructure in meaningful ways, that is, they are deemed 'useful' because participants are able to share in commons (such as, the ownership and co-production of a wireless network).

However, each approach suggested in the paper presents the risk, to various degrees, of being co-opted into the 'creative economy' discourse and thus of impacting on gentrification and displacement. This is particularly the case in urban regeneration linked LL, where the initiatives are largely tokenistic and the ambition is to transform the area into a vibrant digital economy. As noted above, LL can contribute to the creation of 'smart enclaves' (Clark and Shelton 2016), 'cultural quarters' (Keith 2005; Lawton and Punch 2014), and to

21 Here the parallels to the gentrification debate are quite explicit: whereas gentrification is thought as beneficial to the city as a whole thanks to its ability to 'trickle-down' services and well-being to all (see Newman and Wyly, 2006).

22 Another example is the implementation plan for LinkNYC, ad-sponsored multipurpose Wi-Fi kiosks, which were promptly activated in large number in Manhattan, rather than in poorer areas. See: http://nydn.us/2kwzjpC 
direct, exclusionary, and cultural forms of displacement (Marcuse 1985; Newman and Wyly 2006; Slater 2006; Lawton et al. 2014). Whereas the SC discourse is fairly recent, over forty years of gentrification research have laid the ground for understanding the dynamics of capitalist urban development, and for unpacking different forms of displacement. While LL initiatives seem to hinge upon a rather limited temporal horizon, the enduring effects of gentrification are longer term. The paths through which LL initiatives are set within the SC debate raise questions, and the need for longitudinal research, around the risks for modelling urban space in a certain way.

Moreover, we argue that participation and citizen-engagement within LL initiatives are often fairly limited, organised and run within stewardship and civic paternalist frames. Being citizen-led or citizen-engaged in the SC does not necessarily confer notions of citizenship or rights to the digital city, or produce a new digital urban commons. Instead, 'citizen' is someone who pro-actively participates in SC initiatives that are often subsumed into a prepackaged model of participation which depends on the affordance of software interfaces (see also Gabrys 2014). The development and use of participative SC software interfaces seem, in fact, to produce an 'ideal citizen' that willingly subscribes to the idea(l)s of technological solutionism promoted by smart city discourses and acquires the cultural capital necessary to communicate or tinker with smart technologies. While often worthy and much more preferable to top-down and technocratic forms of governance, it is unlikely that LL endeavours in any of its guises will solve the problem of the 'right to the city' (Harvey 2003; Marcuse 2014; Purcell 2002) without this being explicitly rooted in notions of citizenship and community-ownership, rather than citizen-participation and civic paternalism. The root to this, it seems to us, is within a communal city model of citizen engagement.

\section{Acknowledgements}

This paper was prepared for the workshop, 'The New Urban Ruins: Vacancy and the PostCrisis City', 1-3 March 2017, Trinity College Dublin. The research funding for the paper was provided by a European Research Council Advanced Investigator Award, 'The Programmable City' (ERC-2012-AdG-323636).

\section{References}

Aalbers, M.B. 2011. The revanchist renewal of yesterday's city of tomorrow. Antipode 43(5): 1696-1724.

Agyeman, J. and McLaren, D. 2013. Briefing - Sharing Cities. London: Friends of the Earth. Available at: 
https://www.foe.co.uk/sites/default/files/downloads/agyeman_sharing_cities.pdf [Accessed February 10, 2017].

Antoniadis, P. and Apostol, I. 2014. The right(s) to the hybrid city and the role of DIY networking. The Journal of Community Informatics 10(3). Available at: http://cijournal.net/index.php/ciej/article/view/1092 [Accessed May 10, 2015].

Ballon, P. and Schuurman, D. 2015. Living labs: concepts, tools and cases. info 17(4). Available at: http://www.emeraldinsight.com/doi/10.1108/info-04-2015-0024 [Accessed February 16, 2017].

Bonnett, A. 2006. The nostalgias of Situationist subversion. Theory, Culture \& Society 23(5): 23-48.

Bresnihan, P. and Byrne, M. 2015. Escape into the city: Everyday practices of commoning and the production of urban space in Dublin. Antipode 47(1): p.36-55.

Cardullo, P. 2014. Sniffing the city: issues of sousveillance in inner city London. Visual Studies 29(3): p.285-293.

Cardullo, P. 2017. Gentrification in the mesh? Ethnography of Open Wireless Network. City. Available at: http://tiny.cc/9jk1cy.

Castelnovo, W., Misuraca, G. and Savoldelli, A. 2015. Citizen's engagement and value coproduction in smart and sustainable cities. In International Conference on Public Policy, 1-16. Available at: http://www.icpublicpolicy.org/conference/file/reponse/1433973333.pdf [Accessed December 28, 2016].

Clark, J. and Shelton, T. 2016. Technocratic values and uneven development in the 'Smart City'. Metropolitics. Available at: http://www.metropolitiques.eu/Technocratic-Values-andUneven.html [Accessed February 16, 2017].

Corsin Jimenez, A. 2014. The right to infrastructure: a prototype for open source urbanism. Environment and Planning D: Society and Space 32(2): p.342-362.

de Waal, M. 2014. The City as Interface: How Digital Media are Changing the City. Rotterdam: nai010 publishers.

Dodge, M. and Kitchin, R. 2013. Crowdsourced cartography: Mapping experience and knowledge. Environment and Planning A 45(1): p.19-36.

Dutilleul, B., Birrer, F.A., \& Mensink, W. 2010. Unpacking European living labs: Analysing innovation's social dimensions. Central European Journal of Public Policy 4(1): p.60-85.

Florida, R.L. 2007. The Flight of the Creative Class: The New Global Competition for Talent. New York: HarperCollins. 
Foth, M. 2016. Why we should design smart cities for getting lost. The Conversation. Available at: http://theconversation.com/why-we-should-design-smart-cities-for-gettinglost-56492 [Accessed February 3, 2017].

Gabrys, J. 2014. Programming environments: Environmentality and citizen sensing in the smart city. Environment and Planning D: Society and Space 32(1): p.30-48.

Garrett, B.L. 2013. Explore Everything: Place-Hacking the City. London: Verso.

Harvey, D. 2003. The right to the city. International Journal of Urban and Regional Research 27(4): 939-940.

Heaphy, L., and Pétercsák, R. 2016. Building smart city partnerships in the 'Silicon Docks', paper presented at the Creating Smart Cities workshop. In Maynooth University, Ireland. Available at: http://bit.ly/2mjpJUf.

Keith, M. 2005. After the Cosmopolitan? Multicultural Cities and the Future of Racism, London: Routledge.

Kitchin, R. 2016. Impressions of Songdo, an urban growth machine in progress. The Programmable City. Available at: http://tiny.cc/scbkgy [Accessed November 2, 2016].

Kitchin, R., Hearne, R. and O'Callaghan, C. 2015. Housing in Ireland: From crisis to crisis. In Roche, W.K., O'Connell, P. and Prothero, A. (eds) Austerity and Recovery in Ireland: Europe's Poster Child and the Great Recession. Oxford: Oxford University Press. pp. 272289

Lange, M. and de Waal, M. 2013. Owning the city: New media and citizen engagement in urban design. First Monday 18(11). Available at: http://firstmonday.org/ojs/index.php/fm/article/view/4954 [Accessed February 1, 2017].

Lange, M. and de Waal, M. 2016. Hacking Buiksloterham. Available at: http://thehackablecity.nl/.

Lawton, P., Murphy, E. and Redmond, D. 2014. Neoliberalising the city 'creative-class' style. In A. MacLaran and S. Kelly (eds) Neoliberal Urban Policy and the Transformation of the City, 189-202. Palgrave Macmillan UK.

Lawton, P. and Punch, M. 2014. Urban governance and the 'European City': Ideals and realities in Dublin, Ireland. International Journal of Urban and Regional Research 38(3): $864-885$.

Marcuse, P. 1985. Gentrification, abandonment, and displacement: Connections, causes, and policy responses in New York City. Journal of Urban and Contemporary Law 28: 195-240. Marcuse, P. 2014. Reading the right to the city. City 18(1): 4-9. 
Mattern, S. 2016. Instrumental city: The view from Hudson Yards, circa 2019. Places Journal. Available at: https://placesjournal.org/article/instrumental-city-new-york-hudsonyards/ [Accessed January 27, 2017].

McLaren, D. and Agyeman, J. 2015. Sharing Cities: A Case for Truly Smart and Sustainable Cities. MIT Press.

Mengoli, P. and Russo, M. 2017. A hybrid space to support the regeneration of competences for re-industrialization. REPEC, https://ideas.repec.org/p/mod/depeco/0108.html

Newman, K. and Wyly, E.K. 2006. The right to stay put, revisited: Gentrification and resistance to displacement in New York City. Urban Studies 43(1): 23-57.

O’Callaghan, C. and Lawton, P. 2016. Temporary solutions? Vacant space policy and strategies for re-use in Dublin. Irish Geography 48(1): 69-87.

O’Hara, R. 2015. Communities locked out of Docklands future. LookLeft. Available at: http://www.lookleftonline.org/2015/04/communities-locked-out-of-docklands-future/ [Accessed February 21, 2017].

PCAST. 2016. PCAST Releases Technology and the Future of Cities Report to the President. Washington, D.C. Available at: http://bit.ly/2kCclJ9.

Perng, S.Y. 2016. Creating infrastructure with citizens: An exploration of Beta Projects, Dublin City Council. Paper presented at the Creating Smart Cities Workshop, 5th - 6th September, Maynooth University, Ireland. Available at: http://bit.ly/2mjmyfd [Accessed March 13, 2017].

Perng, S.-Y., \& Kitchin, R. 2016. Solutions and frictions in civic hacking: collaboratively designing and building wait time predictions for an immigration office. Social \& Cultural Geography. Online first. 1-20.

Purcell, M. 2002. Excavating Lefebvre: The right to the city and its urban politics of the inhabitant. GeoJournal 58(2): 99-108.

Sartori, L. 2015. Alla ricerca della 'smart citizenship'. Istituzioni del Federalismo: Rivista di Studi Giuridici e Politici (4): 927-948.

Schmidt, S. ed. 2011. Hacking the City. Available at: http://hacking-thecity.org/about/\#Konzept\%20Englisch [Accessed October 6, 2016].

Schuurman, D., De Marez, L. and Ballon, P. 2016. Living Labs: a systematic literature review. Available at: https://biblio.ugent.be/publication/7026155/file/7026171 [Accessed March 10, 2017].

Shelton, T., Zook, M. and Wiig, A. 2015. The 'actually existing smart city'. Cambridge Journal of Regions, Economy and Society 8(1): p.13-25. 
Slater, J. and Iles, A. 2009. No Room to Move: Radical Art and the Regenerate City. Available at: http://tiny.cc/b50ogy [Accessed December 27, 2009].

Slater, T. 2006. The eviction of critical perspectives from gentrification research. International Journal of Urban and Regional Research 30(4): 737-757.

Till, K. and McArdle, R. 2016. The improvisional city: Valuing urbanity beyond the chimera of permanence. Irish Geography 48(1): 37-68.

Vanolo, A. 2014. Smartmentality: The smart city as disciplinary strategy. Urban Studies 51(5): 883-899.

Zuckerman, E. 2016. Desperately seeking serendipity. CHI keynote. Available at: http://www.ethanzuckerman.com/blog/2011/05/12/chi-keynote-desperately-seekingserendipity/ [Accessed February 3, 2017]. 